\title{
Gustatory quality changes as a function of solution concentration
}

\section{ERNEST DZENDOLET AND HERBERT L, MEISELMAN}

UNIVERSITY OF MASSACHUSETTS
Four selected female $S$ s were instructed to respond with the qualities of either bitter, salty, sour, sweet, or no taste to solutions of $\mathrm{LiCl}, \mathrm{KCl}, \mathrm{Li}_{2} \mathrm{SO}_{4}$, or $\mathrm{K}_{2} \mathrm{SO}_{4}$ which varied in concentration from 0.0040 to $0.050 \mathrm{M}$ for the first two salts, and 0.0020 to $0.025 \mathrm{~F}$ for the last two. Mean percentages of each quality, with sweet combined with the no taste response, when plotted against concentration, gave functions in which one quality predominated within a given concentration range. This quality was superseded by another over a higher concentration range. These results are explained in terms of an intibition phenomenon.

Höber and Kiesow (1898) were apparently first to report that a salt solution may change its gustatory quality as a function of its concentration. They used solutions which were kept at $25^{\circ} \mathrm{C}$, and which were presented in order of increasing concentration, i.e., ascending series only, method of limits. They served as their own Ss, and flowed two cc of solution over their tongues from a pipette. They rinsed their mouths with water after each stimulus application. In this experiment, they were primarily interested in the absolute threshold for salty in a number of compounds, rather than in a description of the variations of quality with concentration for a single compound. They did note, however, that many bases or alkalies in dilute solution evoked sweet. They also tested beryllium chloride and beryllium sulfate and found that both compounds evoked sweet over their sapid range, with a sour. component at the higher concentrations.

Renqvist (1919) investigated a number of compounds, specifically for their change of quality with concentration. He also used the method of limits, ascending series mostly, but with some descending series. A $4-\mathrm{cc}$ quantity of distilled water was sipped, expelled and a 4-cc sample of test solution was sipped and then expelled. The quality of the test solution, as compared with the sample of distilled water, was then reported. The reason for this procedure was that the test solution diluted the constituents of the saliva, in addition to presenting the salt. To make a proper judgment as to the quality of the salt, a comparably diluted saliva was considered necessary. This was provided by sipping the same volume of distilled water. The mouth was rinsed with distilled water between these paired presentations of distilled water and test solution. All solutions were apparently at room temperature, and probably only one $\mathrm{S}$ was used for this portion of the investigation, although four Ss were used in an earlier part concerned with absolute thresholds. Renqvist's results showed that potassium chloride, for example, evoked sweet from $0.0090 \mathrm{M}$, the lowest concentration used, to $0.020 \underline{M}$ where it became slightly bitter. It evoked bitter and salty at $0.050 \underline{M}$, turning more salty until $0.3 \underline{\mathrm{M}}$ was reached, where it evoked pure salty. At $0.6 \mathrm{M}$ it was somewhat bitter again, and at $1.0 \mathrm{M}$, the highest concentration used, it had a prickling

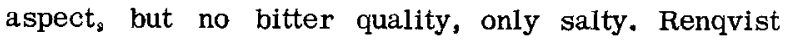
also explored the sodium, lithium and ammonium chlorides, the same bromides and iodides, with the addition of rubidium iodide, the sodium, lithium and potassium acetates, potassium chlorate and perchlorate, potassium fluoride, hydrochloric acid, potassium hydroxide, the barium, calcium and magnesium chlorides, and calcium acetate. In general, there were two or more qualities present except when hydrochloric acid, potassium hydroxide, and calcium acetate were used. In these compounds, hydrochloric acid evoked only sour; potassium hydroxide, only sweet; and calcium acetate, only bitter.

Renqvist also pointed out that adaptation plays a role in determining the quality of a solution. He reported that if an $\mathrm{S}$ held distilled water in his mouth for a period of time and then tasted some of his own saliva, the saliva would have a distinct taste. Renqvist did not report the quality.

The effect of different concentrations of adapting solution on evoked quality as a function of the concentration of the test solution was examined in detail by Bartoshuk, McBurney, and Pfaffmann (1964). They used two practiced Ss and flowed over the tongue, which was extended from the mouth, both the adapting solution, either 0.003 or $0.03 \mathrm{M} \mathrm{NaCl}$, and the test solution, nine values of $\mathrm{NaCl}$ ranging from 0.001 to $0.1 \mathrm{M}$. The solutions were kept at $34^{\circ} \mathrm{C}$, and the Ss could respond only with the categories salt, sweet, sour, bitter, or tasteless.

Their results indicated that, when $0.003 \underline{\mathrm{M}} \mathrm{NaCl}$ was the adapting solution, both Ss tended to report bitter and tasteless to solutions below the adapting concentration. Above that concentration, one $S$ reported the test solutions were sweet, tasteless or salty, with the salty responses increasing in percentage with increase in concentration; the other S, sweet, tasteless, sour, bitter, and salty, with the salty résponses increasing in essentially the same manner as with the first $\mathrm{S}$. With $0.03 \mathrm{M} \mathrm{NaCl}$ as the adapting solution, both Ss reported only salty above the adapting concentration. Below that, one $S$ reported primarily bitter and sour with a little tasteless and sweet in the same general range it was reported with the 
lower adapting concentration. The other S reported essentially the same qualities, but with a greater frequency of tasteless and sweet responses. Distilled water alone was reported as primarily sour and bitter by both Ss with the higher concentration adapting solution, and as either tasteless and sour by one $S$, and bitter, tasteless and sour, primarily bitter, by the other $S$ at the lower adapting concentration. These authors concluded that the quality of a test solution is a function of the adapting solution.

In the current paper, the assumption is made that there are four primary types of receptors, i.e., for the sweet, sour, bitter, and salty qualities as supported by the recent work of Békésy (1964) with electrical stimulation.

\section{Subjects}

\section{METHOD}

These were four undergraduate females at the University, who were non-smokers, and who were not on any medication at the time of the experiment. They were chosen from a group of 23 students, on the basis of their responses to certain gustatory screening stimuli. Ss were paid for participation in both the preliminary and test phases of the experiment.

\section{Stimuli}

Screening stimuli. These were $0.0020 \mathrm{M} \mathrm{HCl}, 0.050$ $\underline{\mathrm{M} \mathrm{NaCl}}, 0.020 \mathrm{M} \mathrm{KCl}$, and $0.015 \mathrm{M}$ sucrose. The salt solutions were made with reagent grade chemicals and locally available distilled water. The sucrose used was an ordinary table sugar. The concentrations of $\mathrm{HCl}, \mathrm{NaCl}$, and sucrose used were within the ranges which permit recognition of the sour, salty and sweet qualities, respectively (Pfaffmann, 1959). KCl was chosen to represent the bitter quality, and the concentration used was chosen on the basis of preliminary testing. The concentrations of the screening solutions were kept low so as to be roughly comparable to the subjective intensities of the qualities assumed to be present in the test solutions. These solutions were kept in a water bath at $35^{\circ} \mathrm{C}$.

Test stimuli. Two of these were 0.0040, 0.0060, $0.0080,0.010,0.020,0.030$, and $0.050 \mathrm{M}$ solutions of $\mathrm{LiCl}$ and $\mathrm{KCl}$. Sets of another two salt stimuli were $0.0020,0.0030,0.0040,0.0050,0.010,0.015$, and 0.025 F solutions of $\mathrm{Li}_{2} \mathrm{SO}_{4}$ and $\mathrm{K}_{2} \mathrm{SO}_{4}$. $(\mathrm{F}$ is defined in terms of gram formula weights per liter of solution, whereas molarity, $\underline{M}$, is defined in terms of gram molecular weights per liter of solution. The use of molarity is theoretically applicable only to substances which exist as molecules in solution. Thus, it is technically incorrect to talk about the molarity of $\mathrm{KCl}$ in solution, because KCl exists as ions and not as molecules. However, the use of molarity in such cases is widespread, and, in addition, carries the implication that the individual ions are present in the same concentration as the indicated molarity. With salts which have a divalent ion, e.g., $\mathrm{K}_{2} \mathrm{SO}_{4}$, the above implication about the concentration of the individual ions is not usually true because of association of some of the ions of the salt, i.e., there can be $\mathrm{K}^{+}, \mathrm{KSO}_{4}{ }^{-}$, and $\mathrm{SO}_{4}=$ ions in the solution in concentrations which are usually not simple multiples of one another. The use of formality to designate the concentration of such salts makes it absolutely clear that no implications concerning ionic concentrations are meant, and yet these concentrations can be easily calculated from the formality when the particular association constant is known.) The concentrations of the last two saits were one-half the concentrations of the first two because an attempt was made to keep the cation concentration approximately the same with both types of salts. These solutions were also kept in a water bath at $35^{\circ} \mathrm{C}$.

The sulfates were chosen because they have been reported by Kusano and Sato (1958), on the basis of electrophysiological studies, as being different in action from common monovalent anions when replacing chloride ion in the Ringer's solution bathing a frog's tongue. The common monovalent anions abolished responses to all taste stimuli after bathing the tongue for an hour, whereas sulfate ion had no such effect. These authors assumed that sulfate neither penetrated the receptor cell membrane, nor otherwise changed its properties. It was considered that in the current experiment, sulfates may exhibit some unique property in terms of quality of responses.

\section{Procedure}

Screening. S was blindfolded upon entering the experimental room and seated before a sink. He was instructed to sip all of the solution $(10 \mathrm{ml})$ presented him in a small glass beaker. He was to hold the solution in his mouth for approximately $3 \mathrm{sec}$., and to spit out the solution into the sink. At this time, $\mathrm{S}$ was to report the quality of the solution and his responses were limited to salty, bitter, sour, sweet, or no taste. The procedure of allowing limited response categories has been used previously by Bartoshuk et al (1964) in gustation, and by Boynton and Gordon (1965) in color vision. The latter paper discussed the advantages of such a procedure. Each of the four screening solutions was presented in a random order for a total of seven presentations of each, with the restriction that no screening solution be presented more than twice in succession. The time interval between presentation was from 90 to 120 sec.

Test. Four Ss were chosen from the 23 screened. The four had responded correctly to each screening stimulus at least five times out of seven presentations. Because $9 \%$ of the total responses of the $23 \mathrm{Ss}$ screened were "no taste," and $65 \%$ of these were given to the sucrose solution, it was decided to combine the responses of no taste with those of sweet as the sucrose score. Instructions to these Ss during the test period were the same as during the 


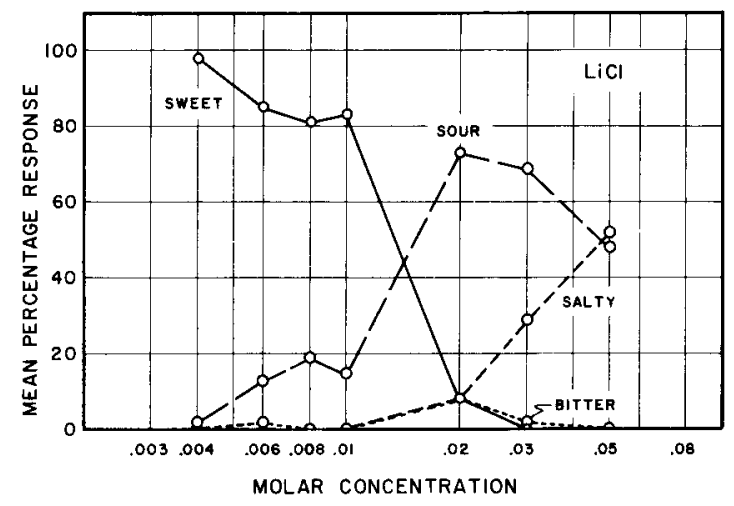

Fig. 1. Mean percentage responses of the four gustatory qualities for four female Ss as a function of concentration of LiCl. The sweet response appears first, then the sour, and finally the salty as the concentration increases.

screening. There were three test sessions, each on a separate day. Each session consisted of four runs through the test stimuli, each set being presented in order of increasing concentration in order to minimize adaptation effects. Only one compound was presented during three consecutive sessions, at the end of which the next compound was given until testing with all four compounds was completed.

\section{RESULTS}

As mentioned earlier, one group of only four of the 23 Ss screened reached the criterion of five out of seven correct responses to the screening solutions. A second group appeared to be homogeneous in that it gave correct responses, but not of as high a frequency as the criterion. The final group was a heterogeneous one composed of Ss who seemed to corfuse the qualities in various ways for reasons as yet unknown.

The percentage of each quality response of $\mathrm{S}$ was determined at each concentration for each of the salts used. The arithmetic mean percentage for the four Ss was calculated and plotted against concentration, separately for the four salts. The results are shown in Figs, 1-4.

Figure 1 shows the responses to $\mathrm{LiCl}$. The sweet responses were very high, above $80 \%$, up to $0.010 \mathrm{M}$ at which concentration the sour response began to increase and the sweet to decrease. Sour responses reached a maximum at $0.020 \underline{\mathrm{M}}$ and began decreasing, whereas salty responses began increasing. Bitter responses remained essentially constant at about $5 \%$ throughout the range of concentrations used.

The responses to $\mathrm{KCl}$, as shown in Fig. 2, were similar to those given to $\mathrm{LiCl}$, except that bitter responses replaced the sour in the mid-concentration range. The sour responses remained essentially constant at about $10 \%$.

Figure 3 shows the responses to $\mathrm{Li}_{2} \mathrm{SO}_{4}$. The primary responses given to this salt were sweet and sour.
As with the other salts, the percentage of sweet responses was high at the lower concentrations and low at the higher ones, whereas the sour responses behaved in the opposite manner. Both salty and bitter responses remained at a low, relatively constant, value throughout.

Responses to $\mathrm{K}_{2} \mathrm{SO}_{4}$ are shown in Fig. 4. The sweet responses occurred in the same general way as with the other salts. Bitter responses with this salt tended to replace the sour responses given with the $\mathrm{Li}_{2} \mathrm{SO}_{4}$, but to a lesser degree. Sour and salty responses both rose at the higher concentrations instead of remaining constant as with the $\mathrm{Li}_{2} \mathrm{SO}_{4}$.

\section{DISCUSSION}

Figures 1-4 display functions which are very similar to those obtained in studies of hue, e.g., Boynton and Gordon (1965), in which there was a consistent change in reported sensory quality with a change in the objective stimulus. Just as in those studies of hue, this study on gustation has given direct evidence of the qualities present, showing that one quality appears to dominate over a concentration range. A possible exception is $\mathrm{K}_{2} \mathrm{SO}_{4}$ (Fig. 4), in which sour and salty had the same percentage of response at the highest concentration used. This percentage was relatively low, however, and the values for the two qualities may have diverged if higher concentrations had been used. Data from each $\mathrm{S}$ on each of the salts showed the same fcrm as the mean curves.

These results of quality change with concentration may be the explanation for an observation reported by von Skramlik (1922). He was able to equate the quality of any salt at a given concentration with a mixture of different concentrations of certain reference substances, i.e., $\mathrm{NaCl}$ for salty, quinine hydrochloride for bitter, glucose for sweet, and tartaric acid for sour. This relationship was expressed as a taste equation of the form: $N=x A+y B+z C+v D$, in which $\mathrm{N}$ indicated the test salt, and the other capital letters indicated the four basic qualities. The coef-

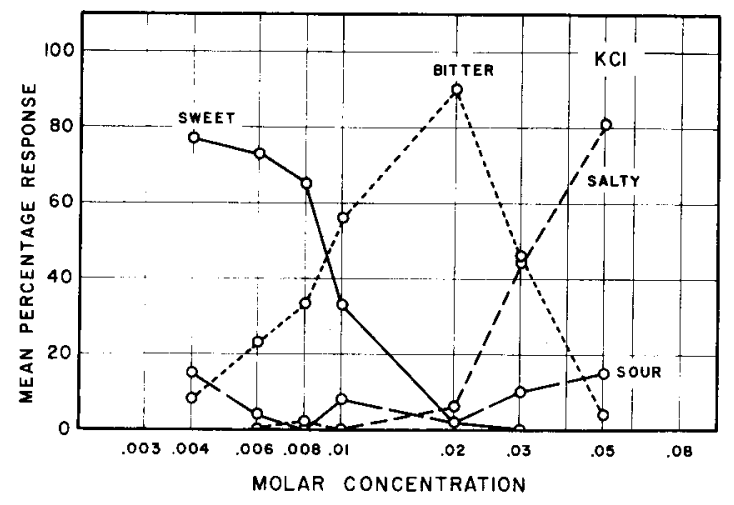

Fig. 2. Same as Fig. 1 except that the salt is $\mathrm{KCl}$. The soui quality of $\mathrm{LiCl}$ appears to have been replaced by bitter. 


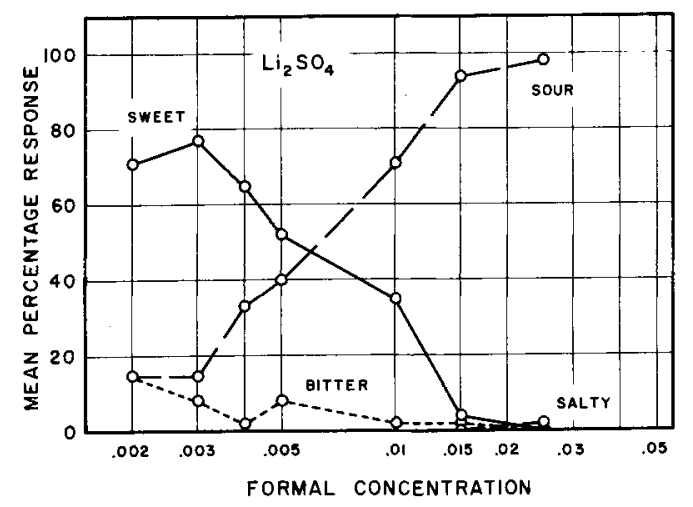

Fig. 3. Same as the earlier figures, except that the salt is $\mathrm{Li}_{2} \mathrm{SO}_{4}$, and the concentration is in formula weights per liter of solution to avoid any implication as to the actual concentration of the different ionic species.

ficients indicated the concentration of the substances evoking these qualities. Skramlik observed that such an equation did not generally hold if the test salt and its equivalent mixture were diluted from the originally matched concentration. It is clear that von Skramlik assumed that dilution of the test salt would change only its intensity, and not its quality. The results of our experiment show that this assumption is not valid. Along this same line, the compounds used for matching the test salt might also have changed quality, almost certainly with the $\mathrm{NaCl}$. Evidence is currently lacking for quality change with concentration in the case of organic compounds.

Because of the difference in the techniques of S'S responding, a strict comparison between the results presented here and those of Renqvist (1919) should not be made. However, for $\mathrm{LiCl}$ the two results do agree generally in that low concentrations evoked

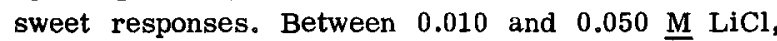
however, Renqvist did not report any sour responses as found in this experiment, but only salty ones. We found that the salty responses began to increase at $0.030 \underline{M}$ rather than $0.040 \underline{M}$ as reported by Renqvist. The results from the two experiments for $\mathrm{KCl}$ agree more closely than for $\mathrm{LiCl}$ in that sweet, bitter, and salty were all present, although the concentration values at which these various qualities appeared were somewhat lower in our experiment.

The difference between these results and those of Békésy (1966) with chemical stimulation of single papillae, are that there was no change in quality with concentration reported in Békésy's experiments. Although Békésy used $\mathrm{NaCl}$, and this experiment used $\mathrm{KCl}$ and $\mathrm{LiCl}$, the two situations can be considered as being comparable. Békésy's concentrations of $\mathrm{NaCl}$ fell within ours for $\mathrm{KCl}$ and $\mathrm{LiCl}$ where sweet and bitter, and sweet and sour were reported, respectively. Renqvist (1919) reported that $\mathrm{NaCl}$ evoked responses of sweet at the lower concentrations and then salty at

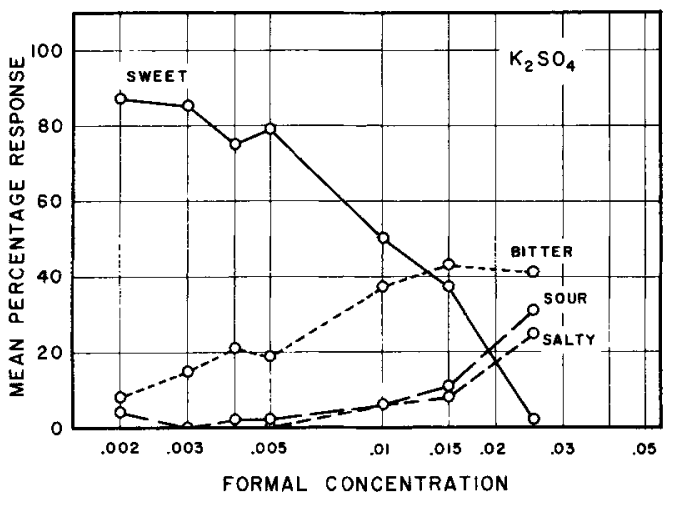

Fig. 4. Same as Fig. 3 , but the salt is $\mathrm{K}_{2} \mathrm{SO}_{4}$. The bitter quality is not as clear in this salt as the sour was with $\mathrm{Li}_{2} \mathrm{SO}_{4}$. The sour and salty qualities have not formed separate peaks at these concentrations with this salt as they have with the other salts.

the higher ones in the same range of concentration values used by us for $\mathrm{LiCl}$ and $\mathrm{KCl}$. We can assume, then, that $\mathrm{NaCl}$ solutions would behave in a manner similar to the $\mathrm{KCl}$ and $\mathrm{LiCl}$ already tested, evoking first sweet and then salty responses. Thus, it would seem that the fact that only one quality was reported in Békésy's experiments must be laid to the situation of having stimulated one papilla, and not to the possibility that only one quality occurred in the concentration range employed.

A possible explanation for the difference in results when using one papilla versus using the whole tongue may be based on the phenomenon reported by Békésy (1959) on studies of cutaneous thresholds. He found that if a vibration of $60 \mathrm{~Hz}$ from a single oscillator were applied simultaneously to the finger tips and to the palm or heel of the hand, the place reported as being stimulated at the lowest absolute threshold was the finger tips. If the vibration amplitude were increased, the place of apparent stimulation moved toward the palm, and reached the palm at $30 \mathrm{~dB}$ above the absolute threshold for the finger tips. Thus, simultaneous stimulation of two groups of receptors which have different absolute thresholds will lead to different localizations, depending on the intensity of the stimulus. The sensation arising from reaching or exceeding the higher-threshold receptor group apparently inhibits the sensations arising from the lower-threshold receptor group.

This inhibitory phenomenon can be applied to the results of the present experiment if two assumptions are made. The first, as stated earlier, is that there are four primary types of gustatory receptors. The second is that a difference in localization is the same as a difference in quality. This assumption appears reasonable if auditory pitch is used as an analogy, because pitch is primarily, although not entirely, due to localization along the cochlear partition. Thus, the shift in localization on the hand in the experiment 
by Békésy (1959) can be considered as equivalent to a change in quality.

This second assumption is also implicit in one of the arguments used by Weddell and his co-workers (Weddell, Taylor, \& Williams, 1955) for their spatiotemporal pattern theory (Lele, Weddell, \& Williams, 1954), whereby the presence of different classes of stimuli need not be detected by specific sensory endings, but only by the neural pattern produced by free nerve endings. Weddell et al (1955) suggested on the basis of degeneration and electrophysiological experiments that localization of a touch stimulus on the rabbit ear could only be signaled by such a spatiotemporal pattern. This same type of mechanism was also presumed to be acting in the case of the warmth, cold, and pain qualities.

In the situation of the present experiment, the shift from one quality to another is, thus, assumed to be caused by different classes of receptors with different absolute thresholds. At low concentrations of the applied salt solution the evoked quality is sweet. This could occur either directly by some structural aspect of the salt solution, or by an adaptation mechanism similar to negative color afterimages as suggested by Bartoshuk et al (1964). At higher salt concentrations, other structural aspects of the solution become intense or concentrated enough to stimulate another group of receptors. When these are stimulated, they inhibit the previously stimulated receptors, thus allowing one quality to be superseded by another. A similar situation may occur at still higher concentrations with another group of receptors.

\section{References}

Bartoshuk, L. M., McBumey, D. H., \& Pfaffmann, C. Taste of sodium chloride solutions after adaptation to sodium chloride: Implications for the "water taste." Science, 1964, 143, 967-968.

Bekésy, G. v. Neural funneling along the skin and between the inner and outer hair cells of the cochlea. J. Acoust. Soc. Amer., $1959,31,1236-1249$.

Bekésy, G. v. Sweetness produced electrically on the tongue and its relation to taste theories. $J$. appl. Physiol., 1964, 19, 11051113.

Bekésy, G. v. Taste theories and the chemical stimulation of single papillae. J. appl. Physiol., 1966, 21, 1-9.

Boynton, R. M., \& Gordon, J. Bezold-Brücke hue shift measurec by color-naming technique. J. Opt. Soc. Amer., 1965, 55, 78-86.

Hober, R., \& Kiesow, F. Ueber den Geschmack von Salzen unc Laugen. Z. physikal. Chemie, 1898, 27, 601-616.

Lele, P. P., Weddell, G., \& Williams, C. M. The relationshif between heat transfer, skin temperature and cutaneous sensibility. J. Physiol., 1954, 126, 206-234.

Pfaffmann, C. The sense of taste. In J. Field, H. W. Magoun \& V. E. Hall (Eds.), Handbook of Physiology, Section 1: Neurophysiology, Vol. I. Washington, D. C.: American Physiological Society, 1959. Pp. 507-533.

Renqvist, Y. Über den Geschmack. Skand. Arch. Physiol., 1919, $38,97-201$.

Skramlik, E. v. Mischungsgleichungen im Gebiete des Geschmacksinns. Z. f. Sinnesphysiol., 1922, 53, 36-78.

Weddell, G., Taylor, D. A., \& Williams, C. M. Studies on the innervation of skin. III. The patterned artangement of the spinal sensory neryes to the rabbit ear. J. Anat., 1955, 89, 317-342.

(Accepted for publication November $1,1966$. ) 